\title{
Mycosis Fungoides and Sezary Syndrome by AJCC v7 Stage
}

National Cancer Institute

\section{Source}

National Cancer Institute. Mycosis Fungoides and Sezary Syndrome by A/CC v7 Stage. NCI Thesaurus. Code C141142.

A term that refers to the staging of mycosis fungoides and Sezary syndrome, following the rules of the TNM AJCC V7 classification system. 